

Korean Journal of Veterinary Research

\section{Original Article}

pISSN 2466-1384 · elSSN 2466-1392

Korean J Vet Res 2021;61(1):e7

https://doi.org/10.14405/kjvr.2021.61.e7

*Corresponding author:

Insik Nam

Division of Applied Bio-Industry Science, School of Animal Life Convergence Science, Hankyong National University, 327 Jungangro, Ansoung 17579, Korea

Tel: +82-31-670-5126

Fax: +82-31-670-5129

E-mail: isnam@hknu.ac.kr

ORCID:

https://orcid.org/0000-0002-3785-315X

Conflict of interest:

The authors declare no conflict of interest.

Received: January 04, 2021

Revised: February 22, 2021

Accepted: March 08, 2021

\title{
Evaluation of the effects of seasonal raw materials and processing stages in feed mills implementing the HACCP system on mycotoxin content in feed
}

\author{
Seung Hee Baek ${ }^{1}$ Insik Nam ${ }^{2, *}$ \\ ${ }^{1}$ Research Center for Environment Friendly and Quality Livestock Production Technology, \\ Hankyong National University, Anseong 17579, Korea \\ 2Division of Applied Bio-Industry Science, School of Animal Life Convergence Science, Hankyong \\ National University, Anseong 17579, Korea
}

The levels of aflatoxin (AFT) and ochratoxin (OCT) were assessed at different seasons in raw materials, different feed manufacture processing stages, and animal feeds in feed mills in Korea implementing the hazard analysis and critical control point (HACCP) system. Two hundred samples were collected in all four seasons from five feed mills implementing the HACCP system and examined for AFT and OCT contents. The AFT and OCT levels were analysed by using HPLC method to provide information on raw material and product stage. The AFT content of raw ingredients in the spring season was highest in corn gluten (3.84 ppb) and lowest in corn (1.82 ppb) The AFT content of corn was highest in the winter season (2.17 ppb). The content of OCT in wheat was highest in the winter season. The amounts of AFT and OCT at processing stages were higher than in the raw materials or feed. In particular, AFT content was higher in the transfer stage (3.88 ppb) than in the mixing ( $2.86 \mathrm{ppb})$ or filling stages $(3.45 \mathrm{ppb})$ in the summer season. The means of AFT and OCT level in laying hen feed was $3.41 \mathrm{ppb}$ and $1.14 \mathrm{ppb}$ for broiler feed, respectively. The means of AFT and OCT level in and broiler feeds was $3.44 \mathrm{ppb}$ and $1.17 \mathrm{ppb}$ for broiler feed, respectively.

Keywords: mycotoxins; aflatoxins; ochratoxins; HACCP; safety

\section{Introduction}

The provision of safe and high quality feeds to domesticated animals is necessary for the health of the animals and for production of safe livestock products for consumers. Feed safety depends on a succession of factors: cultivation practices in countries producing raw materials, storage conditions for materials after production, marine transportation, harbor storage, storage at the feed mill, cleanliness of the manufacturing equipment, and storage conditions of the finished products [1]. In particular, raw materials are easily contaminated with fungi that can produce mycotoxins when stored at high moisture levels [2,3]. In a feed mill, if the raw materials have high moisture contents, they are highly likely to be contaminated with zearalenone; a low moisture content is associated with an increased likelihood of aflatoxin (AFT) contamination [4,5]. Mycotoxin greatly affects livestock productivity. Feeding animals a diet heavily contaminated with AFT can damage their livers, decrease productivity, affect the quality of eggshells in chickens, and reduce carcass quality [6]. AFT also increases the incidence of 
animal disease [7]. Ochratoxin (OCT) in feed is released because of contamination by Aspergillus or Penicillium and has been reported to cause a negative effect on productivity mainly by inducing tumors in the kidneys of pigs and chickens [8]. Mycotoxin has an enormous impact on human health as well as on livestock. In 1993, AFT was designated as a first-level carcinogen and OCT was designated as a second-level carcinogen by the International Agency for Research on Cancer [9].

The deleterious effects of mycotoxin on animal and human health have increased the need for monitoring and management of feed production. In Korea, the safety of feed is controlled on the basis of the Feed Control Act. However, in order to secure the safety of the feed, it was necessary to implement a system that systematically manages all processes in the feed mill. In most countries, good manufacturing practice (GMP) systems have been implemented and are operated in feed mills to ensure production of safe feed. However, feed mills in Korea are implementing a more stringent hazard analysis and critical control point (HACCP) system than the GMP system [10,11]. The HACCP system seeks to control biological, chemical, and physical hazards that may result from processes in the feed mill, animal farm, slaughterhouse, meat processing center, and meat market $[12,13]$. The goal of implementing the HACCP system is to manage potential hazards through prerequisite management program and risk analysis program during food or feed production with a focus on prevention rather than end-product testing [14]. Evaluations in the feed mill under the HACCP system are systematically managed to include all processing stages from storage of raw materials to delivery of products. In particular, the system focuses on the management of mycotoxin contamination, such as AFT, which can occur in the feed mill $[10,11]$. The HACCP system has the potential to have a large effect on the safety of feed produced in Korea. However, little study has been made of mycotoxin levels of raw materials, production stages, and finished products under the HACCP system. Therefore, this study was conducted to evaluate the effectiveness of the HACCP system on controlling mycotoxin levels and seasonal variations in mycotoxin contents of raw materials, during the production stages, and in the finished products.

\section{Materials and Methods}

\section{Sampling}

Eighty raw material samples ( 5 samples in each season for corn, soybean meal, wheat, and corn gluten) were collected from feed mills for analysis of AFT and OCT content. Sixty as- sociated samples ( 5 attached samples in each season at the mixing, transfer and filling stages) were collected from the processing stages to analyze mycotoxin. AFT and OCT levels in broiler and laying hen feeds were assessed in all four seasons using 60 samples. All samples were ground with a grinding mill to produce a homogeneous particle size and stored in a plastic bag in a freezer at $-20^{\circ} \mathrm{C}$ until analysis. Samples were collected at five different feed mills from January to December 2019.

\section{AFT extraction}

Twenty-five grams of the sample was added to $2.5 \mathrm{~g}$ of sodium chloride (Duksan Pure Chemicals Co. Ltd., Korea) and extracted with $100 \mathrm{~mL}$ of acetonitrile:water (86:14, v/v) (J.T. Baker., USA) by blending at high speed for 5 minutes and then filtered through Advantec No. 1 filter paper (Whatman ${ }^{\mathrm{TM}}$ Maidtone, UK). Five $\mathrm{ml}$ of the filtrate sample was diluted with $20 \mathrm{~mL}$ of distilled water and passed through an immunoaffinity column (IAC) (Vicam Nixa, USA). AFT was eluted from the column by applying $1.5 \mathrm{~mL}$ of methanol and the extract was concentrated under nitrogen in a water bath at $50^{\circ} \mathrm{C}$. Then, $200 \mu \mathrm{L}$ of trifluiacetic acid (Sigma-Aldrich, USA) and $800 \mu \mathrm{L}$ of mobile phase (20\% acetonitrile) were added and then derivatized for 20 minutes. The derivatized solution was filtered through a 0.45 $\mu \mathrm{m}$ filter (Milipore, USA) and the filtrate was analyzed.

\section{OCT extraction}

After extraction and filtration as described for AFT, $5 \mathrm{~mL}$ of the filtrate was mixed with $50 \mathrm{~mL}$ of phosphate buffered saline and filtered through a glass microfiber. Ten milliliters of the filtrate was added to $70 \mathrm{~mL}$ acetic acid and passed through an IAC. The sample was eluted from the column by passing through $1.5 \mathrm{~mL}$ methanol. The eluted sample was concentrated under nitrogen in a water bath at $50^{\circ} \mathrm{C}$. The residues were re-dissolved in $1 \mathrm{~mL}$ of the mobile phase, i.e., acetonitrile:water:acetic acid (47:51:2, v/v/v).

\section{Quantitative analysis of mycotoxin by HPLC}

The AFT and OCT standards were obtained from Sigma-Aldrich. Mycotoxin levels of samples were analyzed using an HPLC (Agilent 1200 series; Agilent, USA) with a $\mu$-Bondapak C18 column (Waters Co. Ltd., USA) equipped with a fluorescence detector. The flow rate of the mobile phases for AFT were $\mathrm{H}_{2} \mathrm{O}:$ methanol:acetonitrile $(66: 19: 25, \mathrm{v} / \mathrm{v} / \mathrm{v})$, and for OCT were acetonitrile:phosphoric acid $(1: 1, \mathrm{v} / \mathrm{v})$, and then $0.96 \mathrm{~mL} / \mathrm{min}$ (AFT) and $0.70 \mathrm{~mL} / \mathrm{min}$ (OCT). All solvents used for the preparation of the mobile phase were of HPLC grade and obtained from J.T. Baker. Excitation and emission wavelengths of 
338 and $425 \mathrm{~nm}$, respectively, were used to detect AFT, and 327 and $462 \mathrm{~nm}$, respectively, for OCT. The quantification and detection limits of ATF in the 5 raw material and 2 feed samples were 0.5 to $1.4 \mu \mathrm{g} / \mathrm{kg}$ and 1.8 to $5.5 \mu \mathrm{g} / \mathrm{kg}$, respectively. In addition, OCT were 0.3 to $1.3 \mu \mathrm{g} / \mathrm{kg}$ and 1.7 to $4.5 \mu \mathrm{g} / \mathrm{kg}$, respectively.

\section{Statistical analysis}

Statistical analysis was carried out using the Statistical Analysis System [15]. The effects of seasons and sample origin and timing (raw materials, samples from processing stages and feed samples for broiler and laying hens) on AFT and OCT contents were tested by ANOVA. Duncan's multiple range test was used to confirm significant differences among the mean values of the treatment. Statistical significance was set at $p<0.05$.

\section{Results}

\section{Seasonal AFT and OCT levels of feed ingredients}

Table 1 shows the results of monitoring AFT levels of corn, soybean meal, wheat, and corn gluten, which are commonly used as ingredients for producing animal diets. Most of these were imported from various countries and supplied to animal farms after processing in Korea. AFT content in the dietary ingredients was highest for corn gluten. In particular, mean AFT content of corn gluten imported in spring was $3.84 \mathrm{ppb}$, which was significantly higher than that of corn, soybean meal, and wheat $(p<0.05)$. The AFT content of corn was low in summer and significantly higher in winter $(p<0.05)$. The lowest AFT level for soybean meal was $2.09 \mathrm{ppb}$ and the highest was 3.35 $\mathrm{ppb}$. The AFT content of wheat ranged from a minimum of $1.44 \mathrm{ppb}$ to a maximum of $2.54 \mathrm{ppb}$. Corn gluten had the highest AFT levels among feed ingredients with a minimum of 3.05 ppb and a maximum of $4.65 \mathrm{ppb}$ during the year (Table 1).

The variations in OCT levels among different dietary ingredients (corn, soybean meal, wheat, corn gluten) at different seasons are shown in Table 2. Overall, OCT levels were highest in spring and lowest in summer. OCT levels varied seasonally in the order spring $>$ winter $>$ autumn $>$ summer. The level of OCT in wheat imported in the spring season (2.79 ppb) was significantly higher than at other seasons $(p<0.05)$.

\section{Seasonal AFT and OCT levels of processing stages}

AFT levels at different stages of feed production are presented in Table 3. In general, AFT levels were higher during the processing stages than in the dietary ingredients or finished

Table 1. AFT level of raw materials and seasonal variations in feed mill implementing the HACCP system

\begin{tabular}{|c|c|c|c|c|c|c|}
\hline \multirow{2}{*}{ Season } & \multicolumn{4}{|c|}{ AFT level (ppb) } & \multirow{2}{*}{ SEM } & \multirow{2}{*}{$p$-value } \\
\hline & Corn & Soybean meal & Wheat & Corn gluten & & \\
\hline Spring & $1.82^{* *,++}$ & $2.09^{* *}$ & $2.54^{* * * *}$ & $3.84^{*}$ & 0.29 & 0.038 \\
\hline Summer & $1.47^{t+t}$ & 2.37 & 1.44 & 3.30 & 0.30 & 0.066 \\
\hline Autumn & $1.70^{t+t}$ & 3.28 & 2.48 & 4.65 & 0.69 & 0.538 \\
\hline Winter & $2.17^{+}$ & 3.35 & 2.36 & 3.05 & 0.23 & 0.217 \\
\hline SEM & 0.09 & 0.26 & 0.31 & 0.62 & & \\
\hline$p$-value & 0.006 & 0.215 & 0.632 & 0.853 & & \\
\hline
\end{tabular}

AFT, aflatoxin; HACCP, hazard analysis and critical control point; SEM, standard error of the mean.

****Significant difference in same row.

${ }^{+,++,++}$Significant difference in same column.

Table 2. OCT level of raw materials and seasonal variations in feed mill implementing the HACCP system

\begin{tabular}{|c|c|c|c|c|c|c|}
\hline \multirow{2}{*}{ Season } & \multicolumn{4}{|c|}{ OCT level (ppb) } & \multirow{2}{*}{ SEM } & \multirow{2}{*}{$p$-value } \\
\hline & Corn & Soybean meal & Wheat & Corn gluten & & \\
\hline Spring & 1.45 & 1.82 & $2.79^{+}$ & 1.89 & 0.26 & 0.358 \\
\hline Summer & 0.96 & 1.05 & $1.08^{t+}$ & 0.93 & 0.07 & 0.906 \\
\hline Autumn & 1.01 & 1.08 & $1.28^{+t}$ & 1.19 & 0.08 & 0.658 \\
\hline Winter & 1.08 & 1.39 & $1.54^{++}$ & 1.30 & 0.12 & 0.667 \\
\hline SEM & 0.09 & 0.18 & 0.24 & 0.23 & & \\
\hline$p$-value & 0.182 & 0.088 & 0.020 & 0.556 & & \\
\hline
\end{tabular}

OCT, ochratoxin; HACCP, hazard analysis and critical control point; SEM, standard error of the mean.

${ }^{+,+t}$ Significant difference in same column. 
products. The highest levels were found at the transfer stage (Table 3). AFT levels were significantly higher in the transfer stage compared to other processes in the summer $(p<0.05)$. For the mixing and filling stages, the level of AFT increased in the order spring $>$ winter $>$ autumn $>$ summer, although these differences were not significant. For the transfer stage, AFT levels increased in the order spring $>$ winter $>$ summer $>$ autumn. Overall, AFT levels among the processing stages were highest in spring for transfer process (4.22 ppb).

Changes in OCT levels among processing stages and seasons are shown in Table 4. Average OCT level was lower than AFT level at all stages and seasons. Changes in OCT content among stages and seasons were not significant. However, the processing stage with the highest level of OCT was the transfer stage, as was also the case for AFT. The highest OCT level was found in spring and the lowest in summer, although the differences were not significant. OCT levels in the transfer stage were 2.30 $\mathrm{ppb}$ in spring, $2.22 \mathrm{ppb}$ in summer, and $1.80 \mathrm{ppb}$ in autumn and winter.

\section{Seasonal AFT and OCT levels of poultry feed}

Seasonal changes in AFT and OCT levels in feeds for laying hens and broilers are shown in Table 5. The mean AFT level in laying hen feed was $3.41 \mathrm{ppb}$ and for broiler feed was $3.44 \mathrm{ppb}$. Seasonal variations in AFT contents in the two feeds were simi- lar. The highest levels of AFT were found in spring in both feeds, but there was no statistically significant difference. The lowest levels of AFT were found in summer. Mean OCT content of laying hens and broiler feeds were $1.14 \mathrm{ppb}$ and 1.17 ppb, respectively. The highest OCT levels in laying hen and broiler feeds were found in the spring and the lowest in autumn, but the differences were not significant.

\section{Discussion}

\section{AFT and OCT tolerance levels and statute}

The Feed Control Law of Korea sets the allowable level of AFT in feed at $10 \mathrm{ppb}$ for lactating cows, calf, piglet, and chick, $20 \mathrm{ppb}$ for adult animals, and $50 \mathrm{ppb}$ for raw materials. For OCT, the legal limits are $200 \mathrm{ppb}$ for feed and $250 \mathrm{ppb}$ for raw materials $[10,11]$. The FDA recommends a maximum level of AFT in raw materials of $300 \mu \mathrm{g} / \mathrm{kg}$ in cotton, $300 \mu \mathrm{g} / \mathrm{kg}$ in corn used for beef cattle, $200 \mu \mathrm{g} / \mathrm{kg}$ in corn used for fattening pigs, $20 \mu \mathrm{g} / \mathrm{kg}$ in corn used for lactating cows, and $20 \mu \mathrm{g} / \mathrm{kg}$ for other raw materials [16]. According to the results of our study, the levels of AFT and OCT in the raw ingredients of the feeds were 1.82 and $1.45 \mathrm{ppb}$ for corn, 2.77 and $1.34 \mathrm{ppb}$ for soybean meal, 2.20 and $1.67 \mathrm{ppb}$ for wheat, and 3.71 and $1.33 \mathrm{ppb}$ for corn gluten, respectively. In the case of corn gluten, the mycotoxin content was higher than in raw materials due to the higher pro-

Table 3. AFT levels of processing stages and seasonal variations in feed mill implementing the HACCP system

\begin{tabular}{|c|c|c|c|c|c|}
\hline \multirow{2}{*}{ Season } & \multicolumn{3}{|c|}{ AFT level (ppb) } & \multirow{2}{*}{ SEM } & \multirow{2}{*}{$p$-value } \\
\hline & Mixing & Transferring & Filling & & \\
\hline Spring & 3.40 & 4.22 & 3.82 & 0.19 & 0.248 \\
\hline Summer & $2.86^{* *}$ & $3.88^{*}$ & $3.45^{* * * *}$ & 0.18 & 0.037 \\
\hline Autumn & 3.06 & 3.49 & 3.52 & 0.18 & 0.578 \\
\hline Winter & 3.21 & 3.89 & 3.66 & 0.19 & 0.382 \\
\hline SEM & 0.14 & 0.17 & 0.11 & & \\
\hline$p$-value & 0.630 & 0.552 & 0.738 & & \\
\hline
\end{tabular}

AFT, aflatoxin; HACCP, hazard analysis and critical control point; SEM, standard error of the mean.

***Significant difference in same row.

Table 4. OCT levels of processing stages and seasonal variations in feed mill implementing the HACCP system

\begin{tabular}{lccccc}
\hline \multirow{2}{*}{ Seasons } & \multicolumn{3}{c}{ OCT level $(\mathrm{ppb})$} & \multirow{2}{*}{ SEM } & F-value \\
\cline { 2 - 4 } & Mixing & Transferring & Filling & 0.13 & 0.263 \\
Spring & 1.87 & 2.30 & 1.82 & 0.13 & 0.522 \\
Summer & 1.96 & 2.22 & 1.82 & 0.24 & 0.890 \\
Autumn & 1.49 & 1.80 & 1.70 & 0.18 & 0.911 \\
Winter & 1.87 & 1.80 & 1.65 & \\
SEM & 0.14 & 0.15 & 0.16 & \\
-value & 0.711 & 0.539 & 0.983 & & \\
\hline
\end{tabular}

OCT, ochratoxin; HACCP, hazard analysis and critical control point; SEM, standard error of the mean. 
Table 5. AFT and OCT levels of poultry feeds and seasonal variations in feed mill implementing the HACCP system

\begin{tabular}{|c|c|c|c|c|c|c|c|c|}
\hline \multirow{2}{*}{ Season } & \multicolumn{2}{|c|}{ AFT level (ppb) } & \multirow{2}{*}{ SEM } & \multirow{2}{*}{$p$-value } & \multicolumn{2}{|c|}{ OCT level (ppb) } & \multirow{2}{*}{ SEM } & \multirow{2}{*}{$p$-value } \\
\hline & Laying hen* & Broiler $^{+}$ & & & Laying hen & Broiler & & \\
\hline Spring & 3.67 & 3.74 & 0.11 & 0.800 & 1.40 & 1.48 & 0.180 & 0.853 \\
\hline Summer & 3.16 & 3.10 & 0.10 & 0.788 & 1.02 & 1.07 & 0.07 & 0.784 \\
\hline Autumn & 3.39 & 3.43 & 0.25 & 0.956 & 0.95 & 0.96 & 0.10 & 0.978 \\
\hline Winter & 3.42 & 3.51 & 0.15 & 0.810 & 1.19 & 1.17 & 0.05 & 0.856 \\
\hline SEM & 0.08 & 0.16 & & & 0.08 & 0.11 & & \\
\hline$p$-value & 0.164 & 0.623 & & & 0.151 & 0.427 & & \\
\hline
\end{tabular}

AFT, aflatoxin; OCT, ochratoxin; HACCP, hazard analysis and critical control point; SEM, standard error of the mean.

${ }^{*}$ Mixed laying hen feed (35\% of layer starter $+35 \%$ of layer grower $+30 \%$ of layer).

${ }^{\dagger}$ Mixed broiler feed (50\% of broiler starter $+50 \%$ of broiler finisher).

tein content [17]. The AFT content of edible corn produced in Nigeria is 3.0 to $138 \mathrm{mg} / \mathrm{kg}$ [18], and the AFT content of corn purchased at local shops in Kenya was up to $46,400 \mu \mathrm{g} / \mathrm{kg}$ [19]. In Japan, which imports most of its corn from the US (as does Korea), the AFT content is around 1 to 2 ppb [20]; this is similar to the results in our study. OCT and AFT contents of soybean meal and corn produced as raw materials for poultry feed in the Slavonski area of Europe are $38.78 \mathrm{~g} / \mathrm{kg}$ and $20.00 \mathrm{~g} / \mathrm{kg}$, respectively; these levels are much higher than those in other regions [21]. In the present study, AFT and OCT contents were higher in winter and spring than in summer. Sugiyama et al. [20] and Ismail et al. [22] reported that the AFT content of corn imported in January was higher than in corn imported in June. Dragacci and Fremy [23] also found that AFT content of raw milk in the winter season was higher than in the summer season; this result is similar to the results of this study.

\section{AFT and OCT production in the processing facility}

The AFT and OCT contents of the attached samples from the various stages of feed processing were higher than those of the raw materials and the feeds. Unfortunately, no other studies have examined mycotoxin contents of samples taken from feed processing facilities. However, in a food processing plant that was using corn as a raw material, the mycotoxin content of the corn depended on the temperature and speed of the processing facility [24]. The highest levels of mycotoxin are found in gluten that has been processed as a raw material under high-moisture conditions; mycotoxin levels vary under low moisture conditions depending on whether the fungi penetrate into the interior of the material [5]. According to our results, the AFT and OCT contents of the attached samples from the processing stages were higher than those of raw materials or feeds. In this case, if these materials are mixed into the feed, the mycotoxin content of the feed may exceed the expected level. Therefore, in order to prevent such problems, the production facilities should be periodically cleaned and managed in accordance with HACCP standards for feed mills.

\section{Implementation of HACCP for the management of AFT and OCT in feed}

We found that the mean AFT contents of laying hen and broiler feeds were $3.41 \mathrm{ppb}$ and $3.44 \mathrm{ppb}$, respectively, and the mean OCT contents were $1.14 \mathrm{ppb}$ and $1.17 \mathrm{ppb}$, respectively. Anjum et al. [17] reported that the mean AFT content of broiler feed was $20 \mathrm{ppb}$ and the laying hen feed was $24.5 \mathrm{ppb}$. In general, AFT and OCT contents of poultry feeds produced in Korea are maintained at very low levels. When the AFT and OCT contents exceed $1 \mathrm{ppm}$, egg production is decreased, and feed efficiency is decreased at $2 \mathrm{ppm}$ [25]. In addition, the combination of AFT and OCT has a negative impact on egg quality [26]. Johnson and Parkes [27] suggested that in order to ensure the safety of feed, it is necessary to implement the HACCP system, which is a management system that can identify possible hazards in each processing stage and prevent them in feed mills. In addition, Vlachou et al. [28] reported that the pre-requisite program in the HACCP system implemented in feed mills could decrease the mycotoxin contamination level of the feed. In Korea, the HACCP system at the feed mill combines a prerequisite program and HACCP management. The prerequisite program includes feed mill management, feed manufacturing facility management, feed manufacturing process management, feed hygiene standard, disinfection management, personal hygiene and worker safety, feed storage and handling, feed transportation management, feed inspection facility, feed inspection standard, feed recovery procedure $[10,11]$. The HACCP principle of the feed mills HACCP system in Korea totally follows the CODEX recommendation that consists of five preparation steps (assemble HACCP team, describe product, identify intended use, construct flow diagram and on-site conformation of flow diagram) and seven principles of HACCP 
system (conduct a hazard analysis, determine the critical control point, establish critical limits, establish a system to monitor control of the CCP, establish corrective action to be taken when monitoring indicates that a particular CCP is not under control, establish procedures for verification to confirm that the HACCP system is working effectively and establish documentation concerning all procedures and records appropriate to these principles and application) [14]. Therefore, it would be possible to produce safer feeds by implementing the HACCP system in feed mills [13]. The use of the HACCP system has had a significant impact in Korea in reducing AFT and OCT contents in feed since its introduction in feed mills from 2005. The feed safety is one of important factor to ensure the safety of livestock products. Therefore, in order to secure the safety of feed, it is necessary to manage the feed ingredients, processing and storage stages. In particular, toxins produced by fungi in feed such as aflatoxin reduce the productivity of livestock and negatively affect of human health. This study was conducted to investigate the effects of HACCP implementation on the production of mycotoxins in feed ingredients, processing and storage of poultry feed in Korea. The results of the study showed that the level of mycotoxin in feed is well controlled below the level prescribed by the law but it can be changed according to the season and the environment of the feed ingredients importing country. Our results here indicate that the systematic application of the HACCP system has resulted in stable management of mycotoxins in animal feeds.

\section{ORCID}

Seung Hee Baek, https://orcid.org/0000-0003-0737-7268

Insik Nam, https://orcid.org/0000-0002-3785-315X

\section{References}

1. Pestka JJ, Casale WL. Naturally occurring fungal toxins. Adv Environ Sci Technol 1990;23:613-638.

2. Payne GA. Process of Contamination by Aflatoxin-Producing Fungi and Their Impact on Crops. In: Sinha KK, Bhatnagar D, editors. Mycotoxins in Agriculture and Food Safety. pp. 279306, Marcel Dekker Inc., New York, 1998.

3. Dorner JW. Management and prevention of mycotoxins in peanuts. Food Addit Contam Part A Chem Anal Control Expo Risk Assess 2008;25:203-208.

4. Meister U, Springer M. Mycotoxins in cereals and cereal products: occurrence and changes during processing. J Appl Bot Food Qual 2004;78:168-173.
5. Castells M, Marín S, Sanchis V, Ramos AJ. Fate of mycotoxins in cereals during extrusion cooking: a review. Food Addit Contam 2005;22:150-157.

6. Haschek WM, Voss KA, Beasley VR. Selected Mycotoxins Affecting Animal and Human Health. In: Haschek WM, Rousseaux ECG, Wallig MA, editors. Handbook of Toxicological Pathology. 1. 2nd ed. pp. 645-699, Academic Press, San Diego, 2002.

7. Bryden WL. Mycotoxin contamination of the feed supply chain: implications for animal productivity and feed security. Anim Feed Sci Technol 2012;173:134-158.

8. Bayman P, Baker JL. Ochratoxins: a global perspective. Mycopathologia 2006;162:215-223.

9. International Agency for Research on Cancer. IARC Monographs on the Evaluation of Carcinogenic Risks to Humans. Volume 82. Some Traditional Herbal Medicines, Some Mycotoxins, Naphthalene and Styrene. IARCPress, Lyon (France), 2002.

10. Ministry of Agriculture; Food and Rural Affairs. Feed Standard and Specifications. Notification No. 2017-28. Ministry of Agriculture. Food and Rural Affairs, Sejong, 2017.

11. Ministry of Agriculture; Food and Rural Affairs, HACCP Management Standard of Feed Mill. Notification No. 2019-91. Ministry of Agriculture. Food and Rural Affairs. Sejong, 2019.

12. FAO. Worldwide Regulations for Mycotoxins in Food and Feed in 2003. Food and Agriculture Organization of the United Nations, Rome (Italy), 2003.

13. Baek SH, Kang SC, Lee WC, Nam IS. Effects of HACCP system implementation on domestic livestock product plants. Korean J Food Sci Anim Resour 2012;32:168-173.

14. Codex Alimentarius Commission. Food Hygiene Basic Text. 3rd ed. Codex Alimentarius-Joint FAO/WHO Food Standards Programme, Bernan Association, Lanham, 2001.

15. SAS. SAS/STAT Software for PC. Release 8.2. SAS Institute Inc., Cary (NC), 2010.

16. Richard JL. Some major mycotoxins and their mycotoxicoses--an overview. Int J Food Microbiol 2007;119:3-10.

17. Anjum MA, Khan SH, Sahota AW, Sardar R. Assessment of aflatoxin B1 in commercial poultry feed and feed ingredients. J Anim Plant Sci 2012;22:268-272.

18. Maxwell D, Levin C, Armar-Klemesu M, Ruel M, Morris S, Ahiadeke C. Urban Livelihoods and Food and Nutrition Security in Greater Accra, Ghana. IFPRI, Washington, 2000.

19. Lewis L, Onsongo M, Njapau H, Schurz-Rogers H, Luber G, Kieszak S, Nyamongo J, Backer L, Dahiye AM, Misore A, DeCock K, Rubin C; Kenya Aflatoxicosis Investigation Group. Aflatoxin contamination of commercial maize products 
during an outbreak of acute aflatoxicosis in eastern and central Kenya. Environ Health Perspect 2005;113:1763-1767.

20. Sugiyama K, Hiraoka H, Sugita-Konishi Y. Aflatoxin M1 contamination in raw bulk milk and the presence of aflatoxin B1 in corn supplied to dairy cattle in Japan. Shokuhin Eiseigaku Zasshi 2008;49:352-355.

21. Puntarić D, Bosnir J, Smit Z, Skes I, Baklaić Z. Ochratoxin A in corn and wheat: geographical association with endemic nephropathy. Croat Med J 2001;42:175-180.

22. Ismail A, Riaz M, Akhtar S, Yoo SH, Park S, Abid M, Aziz M, Ahmad Z. Seasonal variation of aflatoxin B1 content in dairy feed. J Anim Feed Sci 2017;26:33-37.

23. Dragacci S, Fremy JM. Contamination du lait par laflatoxine M1: résultats de quinze années de surveillance. Sci Aliments 1993;13:711-722.

24. Katta SK, Jackson LS, Sumner SS, Hanna MA, Bullerman LB.
Effect of temperature and screw speed on stability of fumonisin B1 in extrusion-cooked corn grits. Cereal Chem 1999;76: 16-20.

25. Choudhurv H, Carlson CW, Semeniuk G. A study of ochratoxin toxicity in hens. Poult Sci 1971;50:1855-1859.

26. Verma J, Johri TS, Swain BK. Effect of varying levels of aflatoxin, ochratoxin and their combinations on the performance and egg quality characteristics in laying hens. Asian-Australas J Anim Sci 2003;16:1015-1019.

27. Johnson R, Parkes RR. Ensuring Feed Safety-A Case Study of the Implementation of HACCP into a Commercial Feed Milling Company. Ridley AgriProducts Pty Ltd., Victoria (Australia), 2001.

28. Vlachou S, Zoiopoulos PE, Drosinos EH. Assessment of some hygienic parameters of animal feeds in Greece. Anim Feed Sci Technol 2004;117:331-337. 